\title{
Ontology for Software Metrics and Indicators: Building Process and Decisions Taken
}

\author{
Luis Olsina and María de los Angeles Martín \\ Department of Informatics, Engineering School at UNLPam, Argentina. \\ \{olsinal, martinma\} @ing. unlpam. edu.ar
}

\begin{abstract}
There are various useful ISO standards related to software quality models, measurement, and evaluation processes. However, we observe sometimes a lack of a sound consensus among the same terms in different documents or sometimes absent terms. In [7, 10], our ontology for software metrics and indicators was detailed. In this article, the process and decisions that have been taken during the construction of the ontology are highlighted.
\end{abstract}

\section{Introduction}

Software measurement and even more web measurement are currently in a stage in which terminology, principles, models, and methods are still being defined and consolidated. In order to promote a more mature discipline, it has becomes mandatory to start reaching a common agreement between researchers and other stakeholders about primitive terms such as attribute, metric, measure, measurement and calculation method, scale, elementary and global indicator, calculable concept, among others.

One key factor for the success of our proposed cataloging web system [9] was the conceptualisation of the software metrics and indicators domain formalized by an ontology. Then, our aim was to construct an explicit specification of the conceptualisation for this domain, where concepts, attributes, and their relationships were clearly represented. In this paper, the process and decisions that have been taken during the construction of the ontology are highlighted. We explain why the meaning from one proposal and not from the others was chosen, or why new terms were needed. For this end, the main steps for building the ontology using the Methontology strategy [1] is presented in Section 2. In Section 3, a discussion about decisions taken in choosing the terms is presented. Finally, concluding remarks are drawn.

\section{Methodology for Building the Ontology}

A considerable number of methodologies to build ontologies have been published so far in which different design principles and stages for ontology development were reported. One of the well-known methods is the Methontology strategy [1]. It proposes an effective, generally applicable method for domain knowledge model construction and validation as well. At least, it distinguishes the following steps: Specification, Conceptualisation, Implementation, and Evaluation. 
Specification Step. In a general sense, a sound metrics and indicators specification, flexible documentation, consultation, and retrieval mechanisms are needed in order to contribute to the comprehension and selection process whether metrics and indicators can be useful, easy to collect, and understand. For this end, we argued that a welldesigned repository of metrics and indicators and a semantic web-based cataloging system [9] can be effectively used to support quality assurance processes such as nonfunctional requirement definition and specification, metrics and indicators understanding and selection, amongst others. Therefore having an explicit ontology was a key requirement for our cataloging system.

On the other hand, the sources of knowledge for the proposed metrics and indicators ontology came from our own experience backed up by previous works in metrics and evaluation processes and methods, from different software-related ISO standards, and also from recognized research articles. Taking into account some of his own previous works, Olsina [8] authored the Web Quality Evaluation Method (WebQEM), which is grounded on the design, selection and implementation of metrics, elementary and global indicators and their associated decision criteria, starting from a calculable concept (e.g. quality), and its model. A further research was aimed to specify web metrics, and to develop a conceptual model just for metrics and its cataloging system [9]. Mainly, our ontology has also been inspired in sources as ISO standards and other recognized research articles and books. To quote just a few: The terminology provided in the ISO 15939 standard [5], as well as in the ISO 9126-1 [4], and in the ISO/IEC 14598-1 standards [3].

Conceptualisation Step. Conceptualisation helps to organize and structure the acquired knowledge using external representation languages (such as UML diagrams, tables, classification trees, etc.) that are independent of implementation languages and environments. As results of this step, the metrics and indicators knowledge using a UML conceptual model was yielded, where the main domain concepts, attributes, and relationships were represented (see details in $[7,10]$ ). In table 1 the glossary of terms for the metrics and indicators ontology is explicitaly described.

Implementation Step. To implement the ontology in a formal language, we mainly used $\mathrm{RDF} / \mathrm{S}$, since it is the associated language for ontology implementation with semantic web capability. Implementing the metrics and indicators ontology with semantic web technologies provides more interoperability, automateability, and scalability to our cataloging web system, as discussed elsewhere $[9,10]$.

\section{Discussion About Decisions Taken in Choosing Some Terms}

It is worthy of mention that there are various useful recently issued ISO standards related to software quality models [4], measurement [5], and evaluation processes [3]. The primary aim of these standards was to reach a consensus about the issued models or processes together with a consensus about the used terms; however, they do not constitute themselves a formal or a semiformal ontology.

The ontology for software metrics and indicators we are discussing was based as much as possible on the defined terms of the ISO standards. Specifically, eight terms and their exact meaning out of twenty seven terms of our proposal were fairly used, namely: the attribute [3], decision criteria [5], entity [5], information need [5], 
measurable concept [5] (we used the "calculable" word instead of "measurable" as we discuss later on), measure [3], scale [3], and unit [5] terms. In addition, we employed almost the same meaning to the metric term as in [3], i.e., "the defined measurement and calculation method and the measurement scale". We argue that a direct metric uses just a measurement method meanwhile an indirect metric can use both measurement and calculation methods -an indirect metric is represented by a function or formula that specifies how to combine metrics.

Considering these ISO standards, we have very often observed a lack of sound consensus among the same terms in different documents or sometimes absent terms. For instance, the "metric" term is just used in [3, 4] but not in [5]. Even more, [3, 4] use the terms "direct measure" and "indirect measure" (instead of direct or indirect metric), meanwhile [5] uses "base measure" and "derived measure". In some cases we could state that they are synonymous terms, but in other such as metric, which is defined in [3] as "the defined measurement method and the measurement scale", there is no term with exact matching meaning in [5]. Furthermore, we argue that the measure term is not synonymous with the metric term. The measure term defined in [3] (the meaning we adopted) as "the number or category assigned to an attribute of an entity by making a measurement" or in [5] as "variable to which a value is assigned as the result of measurement" reflects the fact of the measure as the resulting value or output for the measurement activity (or process). Thus, we claim the metric concept represents the specific and explicit definition of the measurement activity.

Besides, we observe some absent terms in these standards such as "elementary indicator" and "global indicator" (even though in [5] the "indicator" term is defined with similar but not equal meaning as in our proposal), as well as the "calculation" and "calculation method" terms that are totally absent. For us, the intended objective for using a measurement method is slightly different for that of using a calculation method. The former is just intended for a measurement activity; the latter, just for a calculation activity.

Focusing us again on the metric term, the metric $\mathbf{m}$ represents the mapping $\mathbf{m : A ~} \mathbf{- >}$ $\mathbf{X}$, where $\mathbf{A}$ is an empirical attribute of one or more entities (the empirical world), $\mathbf{X}$ the variable to which categorical or numerical values can be assigned (the formal world), and the arrow denotes a mapping. In order to perform this mapping a sound and precise measurement (activity) definition is needed by specifying explicitly the method and scale.

On the other hand, a semantic distinction between metric and indicator concepts should be raised. The indicator represents a new mapping coming from the interpretation of the metric's value (formal world) into the new variable to which categorical or numerical values can be assigned (the new formal world). In order to do this mapping a model and decision criteria for a specific user information need is considered. It is interesting to observe the definition of the "rating" term in [3] that says "the action of mapping the measured value to the appropriate rating level" in addition to the "indicator" term in the same document that says "a measure that can be used to estimate or predict another measure". However our meaning for the indicator term (see table 1) is broader in the sense of an explicit definition of the calculation activity needed to produce an indicator value. 
Table 1. Software metrics and indicators ontology: Glossary of Concepts.

\begin{tabular}{|c|c|}
\hline Concept Name & escription \\
\hline Attribute & measurable physical or abstract property of an entity [3]. \\
\hline $\begin{array}{l}\text { Calculable } \\
\text { Concept }\end{array}$ & Abstract relationship between attributes of entities and information needs [5]. \\
\hline Calculation & ctivity that uses an indicator definition in order to produce an indicator's value. \\
\hline $\begin{array}{l}\text { Calculation } \\
\text { Method }\end{array}$ & $\begin{array}{l}\text { The particular logical sequence of operations specified for allowing the } \\
\text { realisation of a formula or indicator description by a calculation. }\end{array}$ \\
\hline Categorical Scale & $\begin{array}{l}\text { A scale where the measured or calculated values are categories, and cannot be } \\
\text { expressed in units, in a strict sense. }\end{array}$ \\
\hline Concept Model & $\begin{array}{l}\text { The set of sub-concepts and the relationships between them, which provide the } \\
\text { basis for specifying the concept requirement and its further evaluation or } \\
\text { estimation. }\end{array}$ \\
\hline \begin{tabular}{|l|} 
Decision \\
Criteria
\end{tabular} & $\begin{array}{l}\text { Thresholds, targets, or patterns used to determine the need for action or further } \\
\text { investigation, or to describe the level of confidence in a given result [5]. }\end{array}$ \\
\hline Direct Metric & A metric of an attribute that does not depend upon a metric of any other attribute. \\
\hline $\begin{array}{l}\text { Elementary } \\
\text { Indicator }\end{array}$ & $\begin{array}{l}\text { An indicator that does not depend upon other indicators to evaluate or estimate a } \\
\text { calculable concept. }\end{array}$ \\
\hline $\begin{array}{l}\text { Elementary } \\
\text { Model }\end{array}$ & $\begin{array}{l}\text { Algorithm or function with associated decision criteria that model an elementary } \\
\text { indicator. }\end{array}$ \\
\hline Entity & Object that is to be characterised by measuring its attributes [5]. \\
\hline Function & Algorithm or formula performed to combine two or more metrics. \\
\hline Global Indicator & $\begin{array}{l}\text { An indicator that is derived from other indicators to evaluate or estimate a } \\
\text { calculable concept. }\end{array}$ \\
\hline Global Model & $\begin{array}{l}\text { Algorithm or function with associated decision criteria that model a global } \\
\text { indicator. }\end{array}$ \\
\hline Indicator & $\begin{array}{l}\text { The defined calculation method and scale in addition to the model and decision } \\
\text { criteria in order to provide an estimate or evaluation of a calculable concept with } \\
\text { respect to defined information needs. }\end{array}$ \\
\hline Indicator Value & $\begin{array}{l}\text { The number or category assigned to a calculable concept by making a } \\
\text { calculation. }\end{array}$ \\
\hline Indirect Metric & $\begin{array}{l}\text { A metric of an attribute that is derived from metrics of one or more other } \\
\text { attributes. }\end{array}$ \\
\hline Information Need & Insight necessary to manage objectives, goals, risks, and problems [5]. \\
\hline Measure & $\begin{array}{l}\text { The number or category assigned to an attribute of an entity by making a } \\
\text { measurement [3]. }\end{array}$ \\
\hline Measurement & Activity that uses a metric definition in order to produce a measure's value. \\
\hline $\begin{array}{l}\text { Measurement } \\
\text { Method }\end{array}$ & $\begin{array}{l}\text { The particular logical sequence of operations and possible heuristics specified for } \\
\text { allowing the realisation of a metric description by a measurement. }\end{array}$ \\
\hline Method & $\begin{array}{l}\text { Logical sequence of operations and possible heuristics, specified generically, for } \\
\text { allowing the realisation of an activity description. }\end{array}$ \\
\hline Metric & The defined measurement or calculation method and the measurement scale. \\
\hline ical Scale & $\begin{array}{l}\text { A scale where the measured or calculated values are numbers that can be } \\
\text { expressed in units, in a strict sense. }\end{array}$ \\
\hline Scale & A set of values with defined properties [3]. \\
\hline Software Tool & $\begin{array}{l}\text { It is a tool that automates partially or totally a measurement or calculation } \\
\text { method. }\end{array}$ \\
\hline Unit & $\begin{array}{l}\text { Particular quantity defined and adopted by convention, with which other } \\
\text { quantities of the same kind are compared in order to express their magnitude } \\
\text { relative to that quantity [5]. }\end{array}$ \\
\hline
\end{tabular}

In addition, we would like to remark the introduction of the terms categorical and numerical scale to our ontology (that are not explicitly specified in the ISO standard). This distinction is important to understand the unit concept associated to scales (see definitions in table 1). Particularly, a categorical scale is a scale where the measured or 
calculated values are categories, and cannot be expressed in units, in a strict sense. Instead, in a numerical scale the values are numbers that must be expressed in units.

Lastly, at the moment of publishing our ontology the closest related work was the recent proposal of the software measurement ontology documented by Genero et al. [2], which was inspired mainly in the terms of the ISO 15939 standard. This work had been a consultation source for our proposal, nevertheless, we have aimed mainly to the metrics and indicators ontology rather than to the measurement process ontology. Our ontology could serve as a subontology for that. In the same direction, with the aim to reach a consensus in a measurement ontology, we were maintaining discussions with different Ibero-American research groups, where a final technical report containing the glossary of terms will be published in 2004 (we held three physical meetings in 2003). As results of the joint discussions we have not yet reach a total agreement in all the terms so far. The main discrepancies are in the metric and indicator terms. Some participants claim that the definition of the metric term is as follows: "a defined measurement form -i.e., a measurement method, or a function, or an analysis model-, and a scale in order to perform measurements of one or more attributes". Moreover, an indicator is a kind of metric (an inheritance relationship). For instance, under this consideration (likewise in [2]), the double mapping for an indicator is not clearly represented. Despite these enriching discrepancies a final joint report will be issued, which could be referenced as another source of knowledge.

\section{Concluding Remarks}

As Kitchenham et al. say [6], without sound and agreed definitions it is difficult to assure metadata consistency and, ultimately, data values are comparable on the same basis. We hope our proposal will have a good diffusion within the software and web communities, and also can serve as a trigger for new enriching discussions as well. The stability and maturity of an ontology can also be judged by the level of agreement reached in a domain-specific international community. This involves the evolveability and perfectibility features of any consensuated knowledge building process.

\section{References}

1. Fernández López, M., Gómez-Pérez, A. and Juristo, N., "METHONTOLOGY: From Ontological Art Towards Ontological Engineering", Proceed. of the AAAI Symposium, California, US, 1997, pp. 33-40.

2. Genero, M.; Ruiz, F.; Piattini, M.; García, F.; and Calero, C.; "An Ontology for Software Measurement", In proceed. of SEKE'03, 15th Int'l Conference on Software Engineering and Knowledge Engineering, San Francisco, US, 2003, pp 78-84.

3. ISO/IEC 14598-1:1999 "International Standard, Information technology - Software product evaluation - Part 1: General Overview".

4. ISO/IEC 9126-1: 2001 "Int'1 Standard, Software Engineering - Product Quality - Part 1: Quality Model".

5. ISO/IEC 15939: 2002 "Software Engineering - Software Measurement Process".

6. Kitchenham B.A., Hughes R.T., Linkman S.G., "Modeling Software Measurement Data", IEEE Transactions on Software Engineering, 27(9), 2001, pp. 788-804. 
7. Martín, M.; Olsina, L., "Towards an Ontology for Software Metrics and Indicators as the Foundation for a Cataloging Web System", In proceed. of IEEE Computer Society (1st Latin American Web Congress), Santiago de Chile, 2003, pp 103-113, ISBN 0-7695-20588.

8. Olsina L., Rossi G., "Measuring Web Application Quality with WebQEM", IEEE Multimedia, 9(4), 2002, pp. 20-29.

9. Olsina, L.; Martin, M. A.; Fons, J.; Abrahao, S.; Pastor, O., "Towards the Design of a Metrics Cataloging System by Exploiting Conceptual and Semantic Web Approaches", In LNCS of Springer, Int'l Conference on Web Engineering (ICWE'03), Oviedo, Spain, LNCS 2722, 2003, pp. 324-333.

10. Olsina, L.; Martín, M.; Ontology for Software Metrics and Indicators, To appear in the Journal of Web Engineering, Rinton Press, NJ, US, 2004. 